\title{
Magnetic, structural and Mössbauer study of soils from an ancient mining area in Huancavelica-Peru
}

\author{
M. A. Castillo Corzo ${ }^{1}$ - L. E. Borja-Castro ${ }^{1}$ - L. De Los Santos Valladares ${ }^{1,2,3}$. \\ J. C. González ${ }^{1}$ · J. Medina Medina ${ }^{1}$ - A. Trujillo Quinde ${ }^{1}$. C. H. W. Barnes ${ }^{2}$. \\ V. A. Peña Rodriguez ${ }^{1}$
}

Accepted: 6 December 2021 / Published online: 22 December 2021

(c) The Author(s) 2021

\begin{abstract}
We present the magnetic, structural and ${ }^{57} \mathrm{Fe}$ Mossbauer characterization of soils collected from an ancient mercury contaminated city named Huancavelica in Peru. The characterization results indicate that silicates and carbonates are the main mineralogical constituents in the samples. In addition, ${ }^{57} \mathrm{Fe}$ Mössbauer spectra at room temperature reveal, the presence of two components: a magnetic component related to magnetic Fe-oxides (magnetite, hematite, goethite) and a high non-magnetic component related to $\mathrm{Fe}^{+3}$ in high spin configuration and tetrahedral coordination in silicates. The magnetization measurements present screening of paramagnetic, ferromagnetic and antiferromagnetic signals, typical from soils containing different silicates and iron minerals. Remarkably the Verwey and Morin transitions corresponding to magnetite and hematite, respectively, are screened by the paramagnetic signal corresponding to the major silicate components in the samples. Overall, the soils are mainly composed of crystalline and amorphous silicates, calcites and iron bearing which are typical from Andean soils.
\end{abstract}

Keywords Mössbauer spectroscopy $\cdot$ Contaminated soils $\cdot$ Iron oxides $\cdot$ XRD · Magnetometry of soils

This article is part of the Topical Collection on Proceedings of the International Conference on the Applications of the Mössbauer Effect (ICAME 2021), 5-10 September 2021, Brasov, Romania Edited by Victor Kuncser

L. De Los Santos Valladares

1d301@cam.ac.uk; luis_d_v@hotmail.com

1 Facultad de Ciencias Físicas, Universidad Nacional Mayor de San Marcos, Ap. Postal 14-0149, Lima, Perú

2 Cavendish Laboratory, Department of Physics, University of Cambridge, J.J. Thomson Ave, Cambridge CB03 0HE, UK

3 School of Materials Sciences and Engineering, Northeastern University, No 11, Lane 3, Wenhua Road, Heping District, Shenyang 110819, People's Republic of China 


\section{Introduction}

Huancavelica is a region located in the central highlands in the South of Peru where one of the main ancient activities is the mining of mercury, gold, silver, zinc and copper. In 1564, the mercury mine called Mina de Santa Barbara was discovered and exploited in 1573 by the Spanish Crown [1]. Since then, between 1564 and 1810 about 17,000 metric tons of mercury vapor $(\mathrm{Hg})$ were released into the environment during the refining of mercury in Huancavelica [2].

Recently, Hagan et al. [2] studied the powder from adobe bricks and dirt floors from different areas in Huancavelica: Santa Ana, Quintanilla Pampa, Yananaco and San Cristóbal in order to evaluate residential $\mathrm{Hg}$ contamination [3]. This work is focused on simulated gastric fluid (GI) extractions and sequential selective extractions (SEEs) of surface dust without inspecting buried soils which is expected to preserve more information of the chemical composition with time. There are no other attempts to characterize contaminated soils from this area.

We present the characterization of soils collected from five different areas in Huancavelica city: Quintanilla Pampa, San Cristobal, Yananaco, Santa Ana and Asención. The samples were collected 200 to $250 \mathrm{~m}$ adjacent to the Ichu River. Four samples were obtained by digging $20 \mathrm{~cm}$ deep the sites of collection and one from a wall adobe. This is a first report about the characterization of soils samples from Huancavelica by Mössbauer spectroscopy and other techniques which is the main contribution and novel support of our work.

\section{Experimental}

Five samples were collected from the Ichu River, Huancavelica Region, Peru with the positions listed in Table 1 . The points of collection lie approximately 200 to $250 \mathrm{~m}$ away from the Ichu River as shown in Fig. 1. The morphology of the samples was inspected through optical microscope (Olympus CX23) with three objectives $\times 10, \times 40$ and $\times 100$ magnification and scanning electron microscope (SEM) Philips XL30. The samples were passed through a sieve of 300 mesh in order to select the fine grains before SEM inspection. SEM resolution was $10 \mathrm{~nm}$ under $30 \mathrm{kV}$ applied voltage and $\times 300000$ magnification. The SEM attached with energy dispersive X-ray (EDX) spectrometer (OXFORD Xplorer).

The X-ray diffraction (XRD) measurements for all the samples were carried out in a Bruker (D8 Focus model) diffractometer in Bragg Brentano geometry using a $\mathrm{Cu}\left(\lambda_{\mathrm{K} \alpha 1}=\right.$ $1.54056 \AA$ ) in the interval $10^{\circ} \leq 2 \theta \leq 70^{\circ}$, with a step of $0.04^{\circ}$ and accumulation time of 4 s/step. The samples were previously ground and sieved (300 mesh) in order to homogenizing the powder. Program Xpert HighScore Plus version 3.0 was used to identify the mineral components.

Mössbauer spectroscopy was carried out at room temperature (RT) using a Mössbauer spectrometer in transmission geometry with a $50 \mathrm{mCi}{ }^{57} \mathrm{Co} / \mathrm{Rh}$ radioactive source moving in constant acceleration. The Mössbauer parameters [isomer shift $(\delta)$, magnetic hyperfine field $\left(\mathrm{B}_{\mathrm{hf}}\right)$, quadrupole splitting $\left(\Delta \mathrm{E}_{\mathrm{Q}}\right)$, quadrupole shift $(2 \varepsilon)$, and absorption area $\left.(\mathrm{A})\right]$ in different Fe sites were obtained fitting the Mössbauer spectra with WinNormos program. The $\delta$-values are relative to RT $\alpha$-Fe value.

The magnetic measurements were carried out using a direct current magnetic properties measurement system (DC-MPMS) which contained a superconducting quantum 


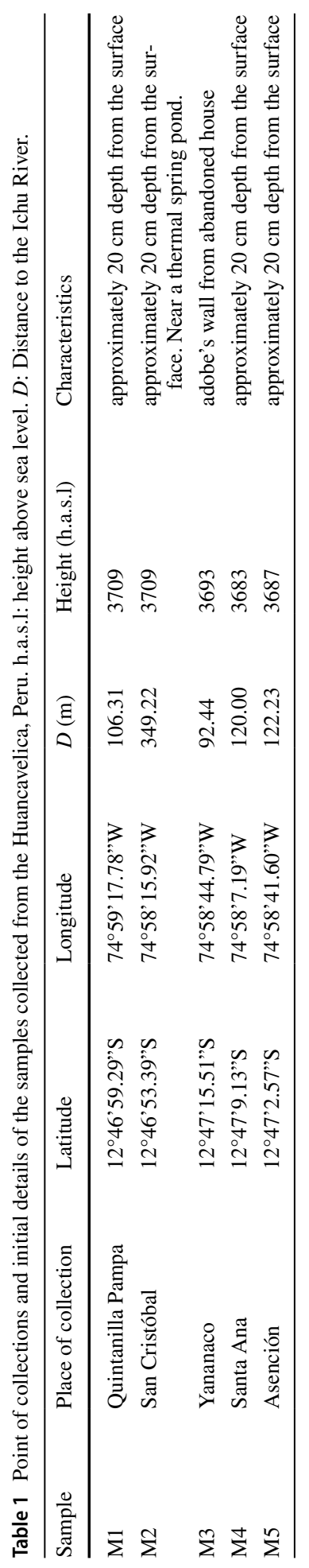




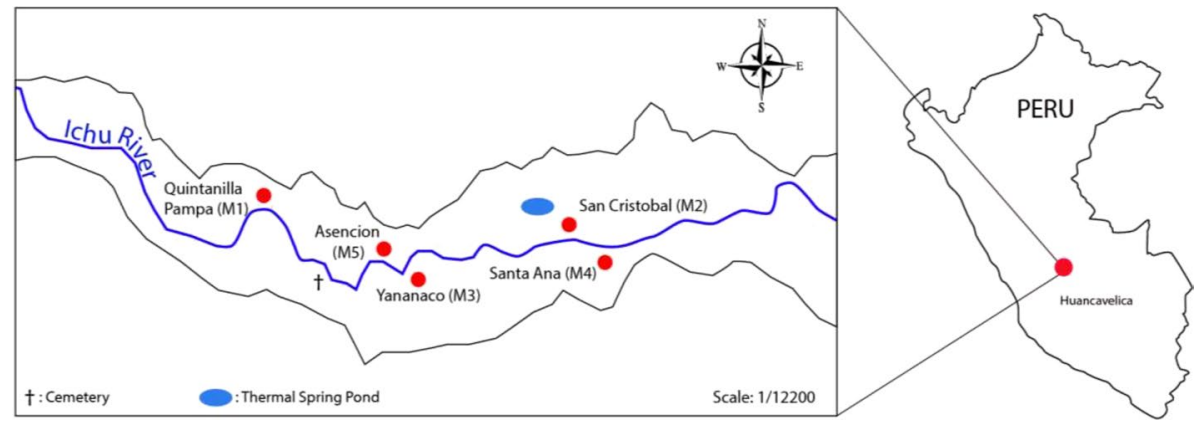

Fig. 1 Map of Huancavelica, Peru. The Ichu River (represented in blue line) cross all the city from West to East. The sites for sample collection are marked as M1, M2, M3, M4 y M5 and listed in Table 1

interference device (SQUID) from Quantum Design Inc. The temperature was set to $8 \mathrm{~K}$ in zero field cooling (ZFC). Then, the data were collected in field heating (FH) and field cooling (FC) modes. The magnetization response as a function of temperature was collected from 5 to $400 \mathrm{~K}$ under an applied magnetic field of $500 \mathrm{Oe}$. The magnetization response as a function of the external magnetic field was also measured in the range $\pm 10 \mathrm{kOe}$ and at 5 and $300 \mathrm{~K}$.

\section{Results and Discussions}

Figure 2 shows the SEM micrographs of the samples together with the EDX mapping micrographs and the chemical analysis obtained by EDX. The SEM image for the sample collected from Quintanilla Pampa (M1) shows dispersed particles of different shapes. The borders of the particles are not round, confirming the results obtained by the optical microscope given in the supplemental material. Despite the samples were not sieved, the size of the particles is approximately $100 \mu \mathrm{m}$, similar to the value obtained by optical microscope above (see supplemental material). In contrast, the SEM micrograph of the sample collected from San Cristobal (M2) shows different particles with different sizes. The biggest one is bigger than $500 \mu \mathrm{m}$. Note that the borders of the particles are not round, confirming the analysis from the optical microscope above (see supplemental material). The SEM micrograph of the sample collected from Yananaco (M3) shows larger broken particles together with tiny particles smaller than $10 \mu \mathrm{m}$. This is not the case for the sample collected from Santa Ana (M4) which shows small particles with sharp and irregular borders with different sizes. For the case of the sample collected from Asención (M5), the micrograph shows two large particles with cracks, suggesting that they are fragile.

Finally, the optical microscope images of the particles shown in Figure S1 (see supplemental information), indicate that the samples of smaller particles are M4 and M5, the particles range from 0.090 to $0.0727 \mathrm{~mm}$. These types of particles possibly have the ability to retain water. Note that all of the micrographs present bright parts probably caused by overcharged areas due to the contains of less conductive components or the presence of organic material. Thus, since the sample M1 presents more bright areas, it might have more insulating components than the other ones. This observation match well with the assumption of larger contains of amorphous silicates than in the other samples observed in the XRD of sample M1 below. 

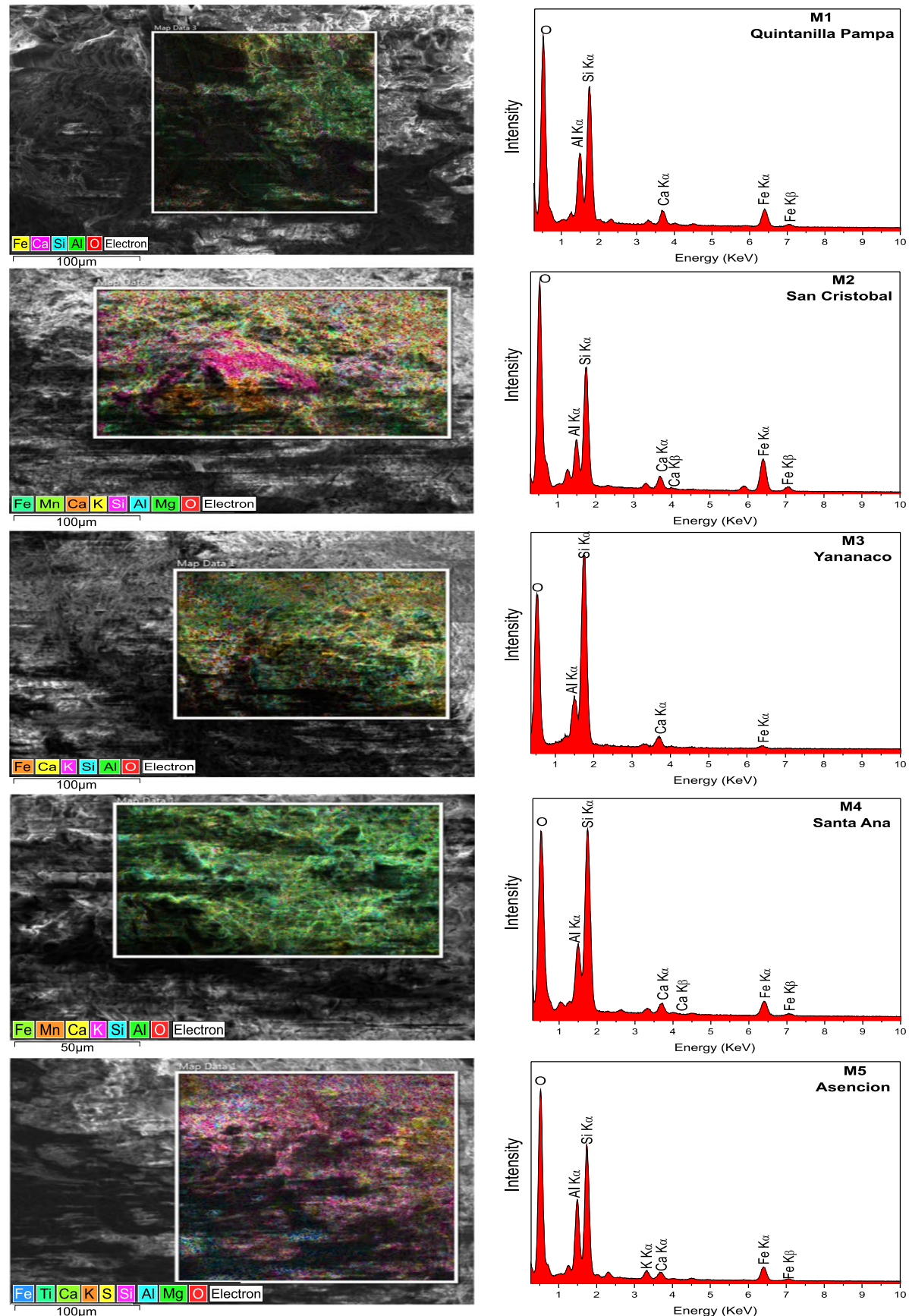

Fig. 2 EDX mapping micrographs (left) and EDX spectra (right) of soil samples collected from an ancient contaminated area, Huancavelica, Peru 
Table 2 Elemental composition in percentage for soil samples collected from Huancavelica, Peru, obtained by EDX (in wt $\%$ )

\begin{tabular}{llllll}
\hline Samples & M1 & M2 & M3 & M4 & M5 \\
\hline Fe & 14.25 & 24.14 & 2.75 & 10.15 & 12.37 \\
$\mathbf{S i}$ & 18.77 & 15.10 & 31.26 & 22.50 & 18.58 \\
$\mathbf{C a}$ & 3.68 & 2.78 & 3.59 & 2.27 & 1.85 \\
$\mathbf{A l}$ & 0.59 & 2.06 & 6.86 & ----- & 6.05 \\
$\mathbf{K}$ & ----- & 1.03 & 0.91 & 0.97 & 1.95 \\
$\mathbf{M n}$ & ----- & 2.94 & ----- & 0.06 & ----- \\
$\mathbf{P b}$ & 0.99 & 0.55 & ----- & ----- & 0.02 \\
$\mathbf{O}$ & 47.33 & 42.83 & 54.18 & 44.87 & 49.00 \\
$\mathbf{B r}$ & 14.38 & 6.50 & ------ & 18.75 & 7.22 \\
$\mathbf{M g}$ & ------ & 1.94 & ----- & ----- & 1.20 \\
\hline
\end{tabular}

The EDX mapping of the samples are presented in the left column in Fig. 2 and was taken over the selected rectangular areas marked in the micrographs. For the sample collected in Quintanilla Pampa (M1), the highlighted colors are yellow, pale blue and scattered pink, corresponding to iron $(\mathrm{Fe})$, silicon $(\mathrm{Si})$ and calcium $(\mathrm{Ca})$, respectively; which are some of the most abundant elements in the sample, as detailed in Table 2. For the sample collected in San Cristobal (M2), the most prominent colors are pink, orange and yellow corresponding to silicon $(\mathrm{Si})$, calcium $(\mathrm{Ca})$ and potassium $(\mathrm{K})$, respectively. Thus, the large pink area in the center is rich in silicon which might correspond to $\mathrm{SiO}_{2}$ as noted in the XRD analysis below. Note that below this zone, there is a remarked orange area, rich in calcium. Other elements, such as manganese $(\mathrm{Mn})$, magnesium $(\mathrm{Mg})$ and Iron $(\mathrm{Fe})$ are spread over all the sample.

For the samples collected in Yananaco (M3) and Santa Ana (M4), the most prominent colors that we observe are: yellow, light blue, green and low intensity pink, all of them correspond to elements such as: calcium $(\mathrm{Ca})$, silicon $(\mathrm{Si})$, aluminum $(\mathrm{Al})$ and potassium $(\mathrm{K})$, respectively. In the sample M3 we can observe the great accumulation of the colors sky blue and green in much of the area shown in the figure suggesting the presence of silicates which is confirmed by XRD below. Due to the presence of oxygen and silicon, the presence of quartz is also inferred and confirmed by XRD below. Likewise, potassium can be observed with very little intensity as detailed in Table 2 . In the micrograph corresponding to the sample M4, we can also observe in the EDX mapping that part of the surface is yellow, light blue and dark green and light green corresponding to $\mathrm{Ca}, \mathrm{Si}, \mathrm{Al}$ and $\mathrm{Fe}$, respectively.

For the sample collected in Asención (M5), the most prominent colors according to the EDX micrograph are pink and light green corresponding to $\mathrm{Si}$ and $\mathrm{Ca}$, respectively, which are the most abundant component. There are large areas with scattered points of light blue corroborating that it also contains Fe.

Overall, we observe and identify some chemical elements that are contained in all the samples, such as silicon, calcium, iron, these are typical components of the soils (see Fig. 3). We observe that the most incident and repetitive element in the five samples analyzed is Fe, in greater proportion, which gives us an idea of that soils are found with iron-based compounds, which are identified with other techniques below.

Figure 3 depicts the most abundant elements found by EDX in all the samples. A complete list of elements found by EDX is given in Table 2. The amount in wt\% for $\mathrm{Si}$ element (represented in red line in the plot) varies in the five samples. According to the 


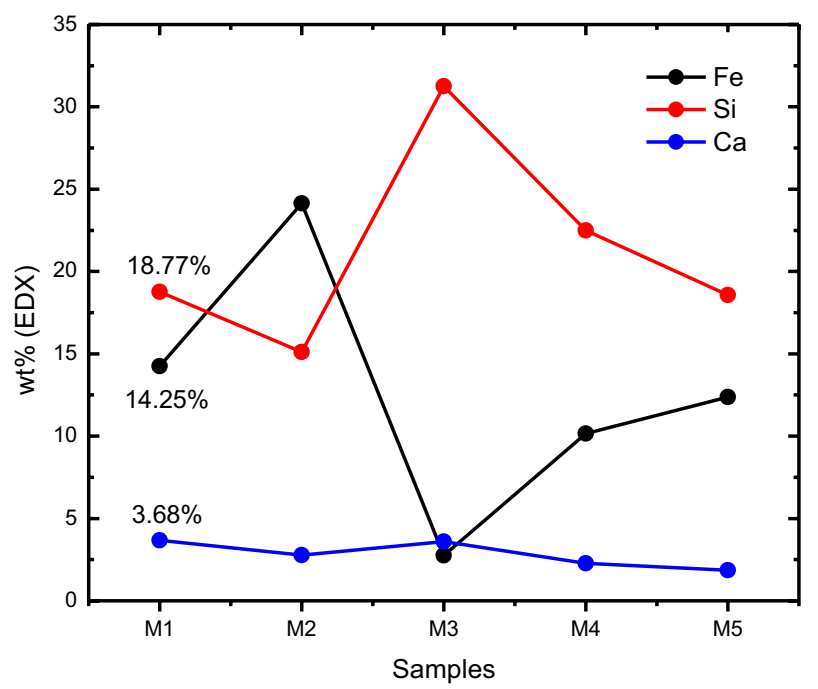

Fig. 3 Major elemental composition of soils samples collected from the districts Quintanilla Pampa (M1), San Cristobal (M2), Yananaco (M3), Santa Ana (M4) and Asención (M5), Huancavelica, Peru

$\mathrm{XRD}$ results, $\mathrm{Si}$ is present in all the samples, but in EDX we observed a lower amount of Si in the M2 sample, because it presents other phases such as goethite and calcium carbonate. Whereas, according the EDX analysis of the M3 sample is corroborated with the XRD below which quartz is one of the main phases.

The amount of the Fe element (black line) varies with sample. The iron signal in the EDX could mainly come from non-magnetic iron silicide minerals and minor amount of iron oxides and hydroxides present in the samples, as suggested by the magnetometry and Mössbauer analysis below. In fact, this is in concordance to the XRD analysis below, in which the presence of Fe is verified in some silicate minerals in samples M1 and M3, while in samples M2, M4 and M5 it is not observed. In contrast to the above elements, the abundance of $\mathrm{Ca}$ (blue line) is almost constant in all the samples. This result is in correspondence to the XRD analysis below, in which $\mathrm{Ca}$ is found in almost all samples with an almost constant percentage, except in sample M4, where Ca cannot be observed, possibly due to the presence of muscovite and albite. Similarly, XRD of samples M2 and M3 reveals the presence of Ca as calcium carbonate (see Fig. 4). Thus, the EDX analysis agree well with the XRD analysis below.

Figure 4 shows the XRD analysis for all the samples. All the diffractograms reveal silicates as main components since all the samples are soils. Among the diffractograms, M1 presents the biggest background, indicating that the soils collected from Quintanilla Pampa (M1) contains more amorphous silicates than the other samples as also suggested by its paramagnetic property discussed in more detail below. In addition, the sample contains crystalline silicates such as quartz $\left(\mathrm{SiO}_{2}, \mathrm{PDF} 2\right.$ card No. 00-001-0649), sanidine ((K,Na) $(\mathrm{Si}, \mathrm{Al})_{4} \mathrm{O}_{8}, \mathrm{PDF} 2$ card No. 00-010-0353) and andradite $\left(\mathrm{Ca}_{3}\left(\mathrm{Fe}^{3+}\right)_{2}\left(\mathrm{SiO}_{4}\right)_{3}\right.$, PDF2 card No. 01-084-1936). Andradite belongs to the group of silicates called nesosilicates containing iron and calcium and is found in various colors, mainly yellow [4].

Andradite is composed of: $\mathrm{Ca}, \mathrm{Fe}, \mathrm{Si}$ and $\mathrm{O}$, and it has chemical composition: silicon oxide $(35.47 \%)$, calcium oxide $(33.11 \%)$ and iron oxide $(31.42 \%)$, which is detected in the 
Fig. 4 X-ray diffractograms for five soil samples collected from ancient contaminated area, in Huancavelica-Peru

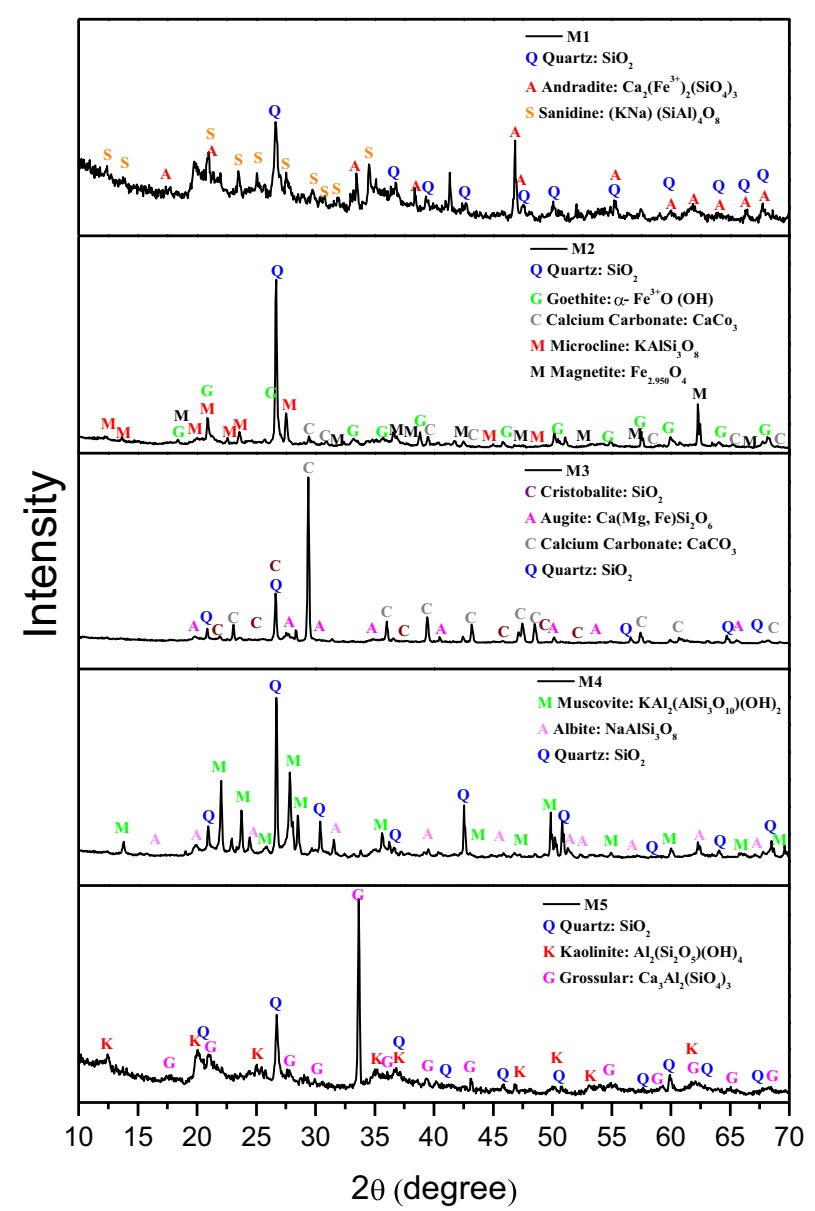

XRD of M1 sample. Whereas, sanidine is high temperature feldspar, characteristic of volcanic lava that crystallize at high temperatures [5].

The sample M2 corresponding to San Cristóbal contains goethite $\left(\alpha-\mathrm{Fe}^{3+} \mathrm{O}(\mathrm{OH})\right.$, PDF card No 00-029-0713). Goethite is a thermodynamically stable iron hydroxide, generally found in soils as a product of the weathering of $\mathrm{Fe}^{2+}$ silicates and commonly found together with quartz, calcite, hematite, among others [6]. In fact, in the present work, quartz, calcite $\left(\mathrm{CaCO}_{3}, \mathrm{PDF} 2\right.$ card No 01-085-1108), microcline ( $\mathrm{KAlSi}_{3} \mathrm{O}_{8}, \mathrm{PDF}$ card No 00-019-0932) and magnetite $\left(\mathrm{Fe}_{2.950} \mathrm{O}_{4}\right.$, PDF card No 01-086-1357) are also detected in the corresponding X-ray diffractogram. The presence of goethite and magnetite are confirmed by Mössbauer analysis below.

The M3 sample corresponding to Yananaco contains cristobalite $\left(\mathrm{SiO}_{2}, \mathrm{PDF}\right.$ card No 01-076-0938) which has the same formula of quartz but with different crystalline structure and it is commonly found in soils. Augite is also detected in the XRD of this sample with the chemical formula $\left((\mathrm{Ca}, \mathrm{Na})(\mathrm{Mg}, \mathrm{Fe}, \mathrm{Al})(\mathrm{Si}, \mathrm{Al})_{2} \mathrm{O}_{6}, \mathrm{PDF}\right.$ card No 00-024-0203) which explains the presence of the iron, silicon, calcium, aluminum and oxygen in the EDX analysis above. In the augite structure, $\mathrm{Fe}^{2+}$ share occupancy with $\mathrm{Mg}$ and $\mathrm{Al}$ but in low percentage $(\sim 4 \%)$ preventing the arrangement of spins in a strong magnetic manner. 

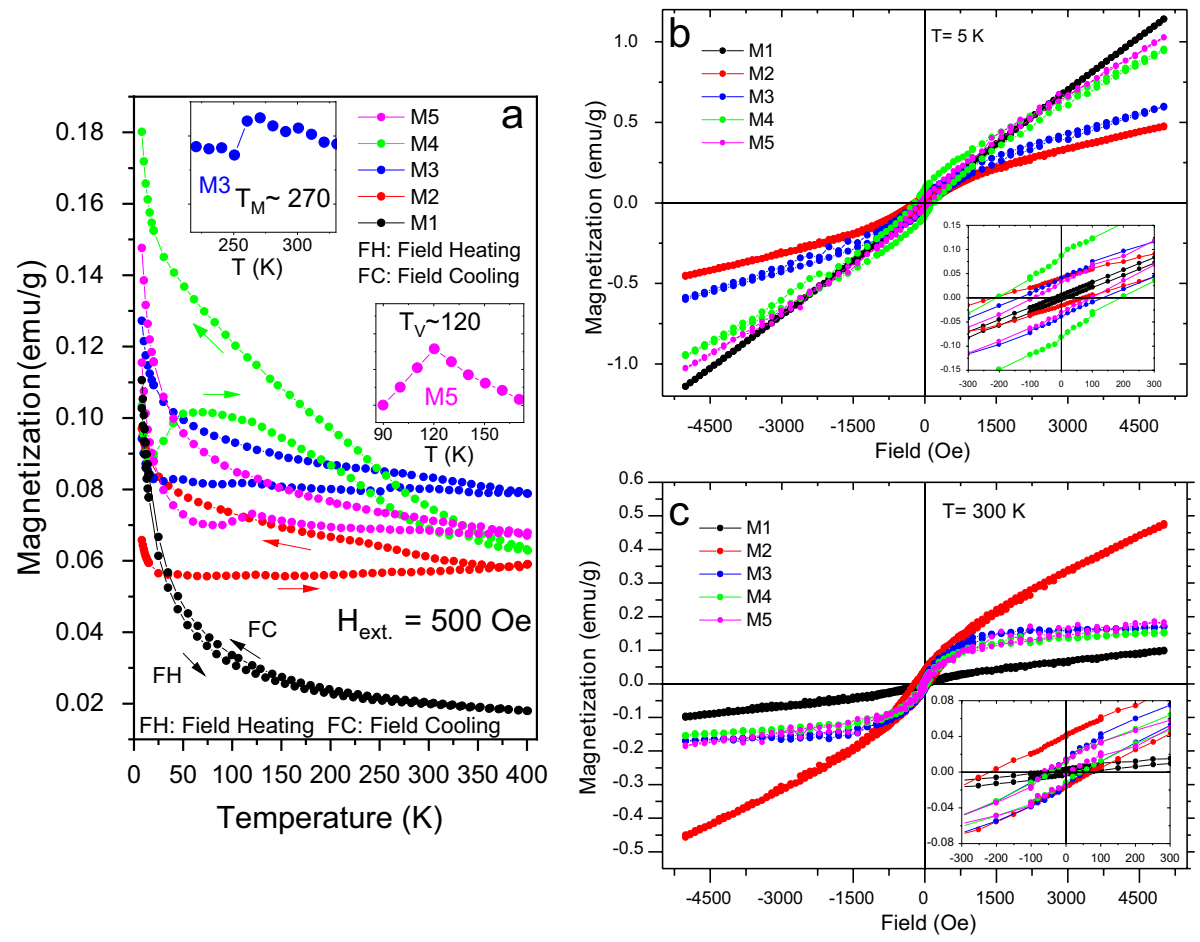

Fig. 5 FH and FC M(T) signals obtained under 500 Oe applied field (insets: zoomed ZFC loops showing magnetic transitions) (a) and $\mathrm{M}(\mathrm{H})$ loops at $5 \mathrm{~K}$ (b) and at $300 \mathrm{~K}$ (c) (insets: zoomed loops in the applied field range \pm 300 Oe)

Moreover, its remanent magnetization and low saturation field, implies that its electronic magnetic moment is weak and it would produce small hyperfine fields in addition to the little amount of Fe. That is why it is not detected in the Mossbauer analysis below [7]. This sample, also presents higher amount of calcium carbonate $\left(\left(\mathrm{CaCO}_{3}\right.\right.$, PDF card No 01-08511-08) than the other samples suggesting that it might come from rest of bones. Note that this place is close to the municipal graveyard of the city.

The M4 sample corresponding to Santa Ana contains quartz, albite and muscovite $\left(\left(\mathrm{KAl}_{2}\left(\mathrm{AlSi}_{3} \mathrm{O}_{10}\right)(\mathrm{OH})_{2}\right)\right.$, PDF card No 01-082-0577) common from soils. The highest reflection corresponds to quartz indicating its higher amount than the other components. This is in agreement with the EDX analysis above which gives high wt $\%$ of its corresponding $\mathrm{Si}$ and $\mathrm{O}$ atoms composition.

According to the XRD analysis, the M5 sample corresponding to Asención contains grossular $\left(\mathrm{Ca}_{3} \mathrm{Al}_{2}\left(\mathrm{SiO}_{4}\right)_{3}\right.$, PDF card No. 01-073-2372), quartz and kaolinite $\left(\mathrm{Al}_{2}\left(\mathrm{Si}_{2} \mathrm{O}_{5}\right)\right.$ $(\mathrm{OH})_{4}$, PDF card No. 00-029-1488). About kaolinite, it is rarely, if ever, pure, but generally contains a small percentage of Fe which occupies primarily the octahedral sites in the structure or isomorphically replacing $\mathrm{Al}$ [8], [9] and [10]. which are classical components of soils. Note that similar to the sample M1 above, the background of the XRD for this sample suggests that it contains a high number of amorphous silicates. Overall, the XRD analysis of the samples indicate that $\mathrm{Fe}$ is found as a constituted element in silicate minerals rather than in iron oxides or hydroxides, especially in the samples M1, M2 and M3. No 
Table 3 Magnetic parameters obtained from the $\mathrm{M}(\mathrm{H})$ loops shown in Fig. 5

\begin{tabular}{|c|c|c|c|c|}
\hline \multirow[t]{2}{*}{ Sample } & \multicolumn{2}{|l|}{$\mathrm{T}=300 \mathrm{~K}$} & \multicolumn{2}{|l|}{$\mathrm{T}=5 \mathrm{~K}$} \\
\hline & $M_{\mathrm{r}}(\mathrm{emu} / \mathrm{g})$ & $H_{\mathrm{c}}(\mathrm{Oe})$ & $M_{\mathrm{r}}(\mathrm{emu} / \mathrm{g})$ & $H_{\mathrm{c}}(\mathrm{Oe})$ \\
\hline M1 & $0.0028(2)$ & $51(5)$ & $0.0045(1)$ & $15(3)$ \\
\hline M2 & $0.028(3)$ & $148(5)$ & $0.023(2)$ & $151(5)$ \\
\hline M3 & $0.013(2)$ & $50(4)$ & $0.038(3)$ & $150(7)$ \\
\hline M4 & $0.011(2)$ & $50(3)$ & $0.081(3)$ & 201(3) \\
\hline M5 & $0.015(2)$ & 40(3) & $0.028(2)$ & $90(5)$ \\
\hline
\end{tabular}

iron oxides such as magnetite or hematite are detected by XRD maybe by its low amount making their reflections to lost in the background of the diffractograms. Nevertheless, they are recognized by their magnetic transitions and Mossbauer analysis, as being discussed in more detail below. Therefore, the major composition of the samples is silicate, as expected since they are soils.

Figure 5(a) shows the field heating (FH) and field-cooled (FC) curves of the temperature dependence of the magnetization $(\mathrm{M}(\mathrm{T}))$ of the samples taken under 500 Oe applied field. Note that the curve for the sample M1 shows the most paramagnetic behavior among the other samples. In fact, the FH and FC loops are almost reversible without revealing any magnetic transition over the whole range of temperature. This was expected, since the XRD analysis discussed above revealed that this sample contains high amount of amorphous silicate. Moreover, the Mössbauer spectroscopy below also suggests that the $\mathrm{Fe}^{3+}$ ions are in paramagnetic state (doublets). The presence of superparamagnetic particles is discarded since the values of the magnetization are very low and there is not any signal at low temperatures suggesting blocking magnetic states.

The applied field dependence of the magnetization $(\mathrm{M}(\mathrm{H}))$ loops taken at 5 and $300 \mathrm{~K}$ (See Figs. 5(b) and (c), respectively) corresponding to this sample do not show hysteresis, confirming the paramagnetic behavior.

For the sample M2, the paramagnetic signal, assumed to come from the silicates, is observed at low temperatures until $25 \mathrm{~K}$. Above this temperature the $\mathrm{FH} \mathrm{M}(\mathrm{T})$ curve becomes nearly constant because the presence of antiferromagnetic goethite found by XRD above and ferrimagnetic magnetite suggested by Mössbauer spectroscopy below. Their magnetic alignment prevents the magnetization values to decay with temperature. Note that at $300 \mathrm{~K}$, the $\mathrm{M}(\mathrm{H})$ presents hysteresis with the highest remanence magnetization $\left(M_{\mathrm{r}}\right)$ and coercive fields $\left(H_{\mathrm{C}}\right)$ than the other samples indicating that this is the most magnetic sample than the other ones at room temperature. Table 3 lists the magnetic parameters obtained from the $\mathrm{M}(\mathrm{H})$ curves for all the samples. Note that the remnant magnetization $\left(M_{\mathrm{r}}\right)$ and the coercive field $\left(H_{\mathrm{C}}\right)$ values taken when reversing the direction of the applied field do not match, to name $M_{\mathrm{r}}(+)$ is $0.039(3) \mathrm{emu} / \mathrm{g}$ and $M_{\mathrm{r}}(-)$ is $-0.017(1)$ is emu/g, whereas, $H_{\mathrm{C}}(+)$ is $75(5)$ Oe. and $H_{\mathrm{C}}(-)$ is $220(1)$ Oe. These differences reveal exchange bias $\left(\Delta H_{\mathrm{C}}=-145(5)\right)$ at $300 \mathrm{~K}$ coming from the magnetic competition between the ferrimagnetic and antiferromagnetic domains.

Note that sample M3 shows a similar magnetic signal to sample M2. The FH M(T) curve also presents a small kick at around $270 \mathrm{~K}$ which is the Morin temperature corresponding to hematite. Thus, even though hematite has not been detected by the XRD analysis above, its presence in this sample is revealed by its magnetic transition from antiferromagnetic to weak ferromagnetic (see corresponding inset in the plot) and it is also confirmed by the Mössbauer analysis below. However, in the plot, the magnetic 

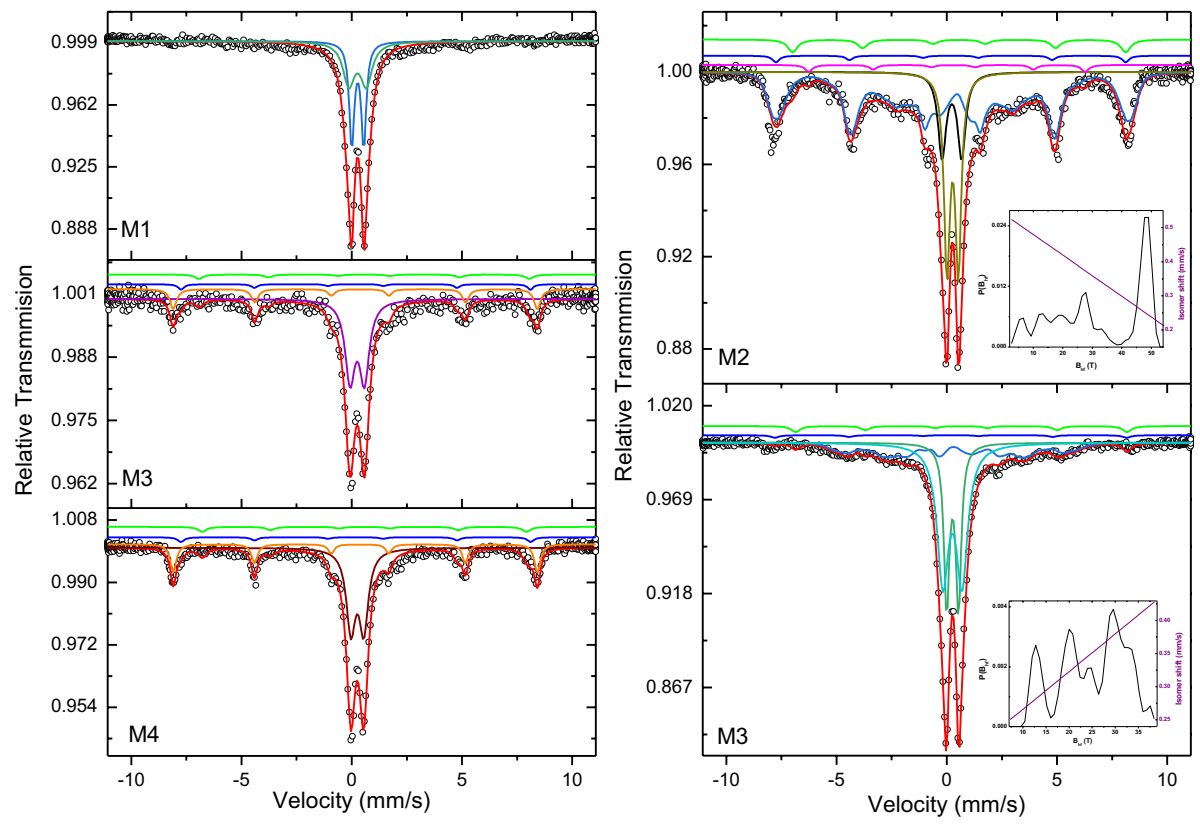

Fig. 6 Mossbauer spectra for five soil samples collected from an ancient contaminated area, Huancavelica Perú

signals of the other components increase the magnetization values and thus the Morin transition seems screened. Furthermore, the $\mathrm{M}(\mathrm{H})$ loops show hysteresis at 5 and 300 $\mathrm{K}$. The hysteresis observed at $300 \mathrm{~K}$ is mainly caused by the weak ferromagnetic alignment of the hematite. Besides, at $5 \mathrm{~K}$ the hysteresis becomes hard because the presence of ferrimagnetic domains belonging to magnetite which is suggested by the Mössbauer spectroscopy analysis below.

The M(T) curves for the sample M4 show the coexistence of paramagnetic and ferrimagnetic phases. The paramagnetic signal is better detected at low temperatures. However, in the temperature range $15 \mathrm{~K}$ to $50 \mathrm{~K}$, the magnetization values increase because the presence of the ferrimagnetic domains. This might come from magnetite as suggested by the Mossbauer spectroscopy below and prevents an abrupt exponential decay of the magnetization values with temperature in the ZFC curves. At higher temperatures than $50 \mathrm{~K}$, the magnetization values decrease since the thermal energy of the crystals increases and the ferrimagnetic alignment of the spins weakens. In fact, this behavior is also confirmed by the hysteresis formed in the $\mathrm{M}(\mathrm{H})$ loops which decreases with increasing temperature. Remarkably, the strong hysteresis loop shown at $5 \mathrm{~K}$ for sample 4, indicates that this sample is more ferrimagnetic than the others at this temperature.

The $\mathrm{M}(\mathrm{T})$ curve for the sample M5 shows a strong paramagnetic signal which might come from the amorphous silicates present in this sample. However, a transition is observed at $120 \mathrm{~K}$ which is the Verwey temperature $\left(T_{\mathrm{V}}\right)$. This indicates that in addition to paramagnetic components, the sample contains magnetite which is not be able to be detected by the other techniques because its low amount. The corresponding $\mathrm{M}(\mathrm{H})$ loops shows typical hysteresis of $\mathrm{Fe}_{3} \mathrm{O}_{4}$ coexisting with other magnetic domains. In general, in contrast to the XRD analysis above, the magnetic measurements suggest the presence of 


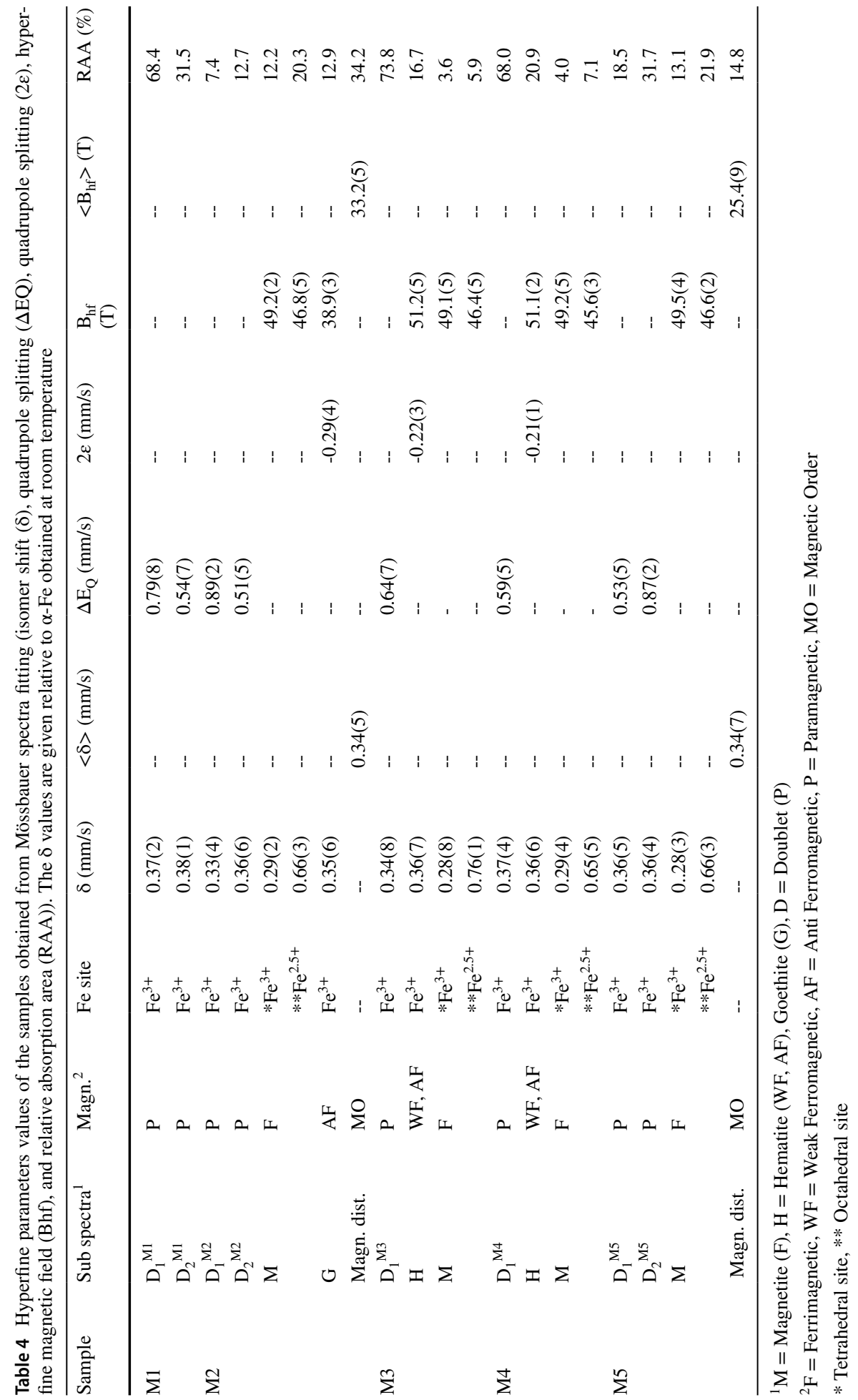


iron oxides in many of the samples since their magnetic alignment persist although being screened by the paramagnetic signals from the majority silicates components.

Considering that all soils samples in the present work contain Fe and Mössbauer spectroscopy is sensitive to changes on Fe environments by measuring their hyperfine interactions thus, the local Fe environment changes in the samples were systematically studied by taking RT transmission Mössbauer spectra of ${ }^{57} \mathrm{Fe}$.

Figure 6 shows the RT Mössbauer spectra for all the samples. For the fitting, the results obtained by EDX, XRD and magnetometry above were considered. In general, the spectra show magnetic and non-magnetic parts, except for the spectrum corresponding to the sample M1, which has only a non-magnetic part. The magnetic part of each spectrum in Fig. 6 display broad six-line patterns due to nuclear Zeeman interaction [an interaction between nuclear magnetic moment and magnetic hyperfine field $\left(\mathrm{B}_{\mathrm{hf}}\right)$ at Fe nucleus], whereas the non-magnetic part in the central areas display broad doublets taking into account the decoupled Fe magnetic moments in all soil samples [11].

The magnetic components of the Mössbauer spectra for the samples M2, M3, M4 and M5 were fitted using three sextets related to the crystalline magnetic Fe sites, two of them correspond to magnetite. Moreover, in the fitting of the spectra for the samples M2 and M5 a magnetic distribution $\mathrm{P}\left(\mathrm{B}_{\mathrm{hf}}\right)$ of 40 non-equivalents of Fe sites associated to disordered $\mathrm{Fe}$ phases was considered. To account for small asymmetries of the spectra, a linear correlation between $\mathrm{B}_{\mathrm{hf}}$ and the isomer shift $(\delta)$ was assumed for the 40 magnetic sub-spectra in $\mathrm{P}\left(\mathrm{B}_{\mathrm{hf}}\right)$. Hyperfine parameters for all the soils samples are listed in the Table 4 [isomer shift $(\delta)$, quadrupole shift $(2 \varepsilon)$, quadrupole splitting $\left(\Delta \mathrm{E}_{\mathrm{Q}}\right)$, hyperfine magnetic field $\left(\mathrm{B}_{\mathrm{hf}}\right)$, and relative absorption area (RAA)]. The $\delta$ values are given relative to $\alpha$-Fe obtained at room temperature (RT).

RT Mössbauer spectrum of the sample M1 was fitted using two paramagnetic doublets associated with $\mathrm{Fe}^{3+}$ cations in silicates such as andradite [12], as suggested in the XRD above. M1 is the only sample that has no magnetic order at RT. This result is in agreement with the ZFC magnetization curve discussed above.

The Mössbauer spectrum at RT for the sample M2 was fitted using: (1) two magnetic sextets associated to magnetite, (2) one sextet with quadrupole shift corresponding to goethite [13], (3) one distribution of 40 magnetic hyperfine fields $\mathrm{P}\left(\mathrm{B}_{\mathrm{hf}}\right)$ associated to disordered $\mathrm{Fe}$ oxides and hydroxides, and (4) one paramagnetic doublet. The two sextets of magnetite $\mathrm{B}_{\mathrm{hf}}=$ 46.8(5) $\mathrm{T}$ and $\mathrm{B}_{\mathrm{hf}}=49.2(2) \mathrm{T}$ correspond to the mixed valence $\mathrm{Fe}^{2.5+}$ (in octahedral site) and to $\mathrm{Fe}^{3+}$ (in tetrahedral site), respectively (see Table 4). The majority absorption area in the M2 spectrum corresponds to magnetite (32.8\%). The sextet with $\delta=0.35(6) \mathrm{mm} / \mathrm{s}, \mathrm{B}_{\mathrm{hf}}=38.9(3)$ $\mathrm{T}$ and $2 \varepsilon=-0.29(4) \mathrm{mm} / \mathrm{s}$ is associated to the goethite which is characterized by its antiferromagnetic behaviour below its Neel temperature $(\sim 400 \mathrm{~K})$. Note that the relative content of magnetite to goethite in M2 is 2.54 This supports the reason why the paramagnetic signal in the corresponding $\mathrm{M}(\mathrm{T})$ curve above does not decay exponentially with temperature, since it is screened by ferrimagnetic and antiferromagnetic signals corresponding to the magnetite and the goethite, respectively. The inset of the Mössbauer spectrum presents the hyperfine magnetic field distribution $\mathrm{P}\left(\mathrm{B}_{\mathrm{hf}}\right)$ on the left axis. The linear correlation between $\mathrm{B}_{\mathrm{hf}}$ and the isomer shift $(\delta)$ of the 40 magnetic sub-spectra used in $\mathrm{P}\left(\mathrm{B}_{\mathrm{hf}}\right)$ are shown on the right axis.

The Mössbauer spectra for the samples M3 and M4 were both fitted by using: (1) one paramagnetic doublet, (2) two crystalline sextets assigned to magnetite and (3) a sextet corresponding to hematite. In both samples M3 and M4, the main component is a paramagnetic doublet. The RAA of the doublets for samples M3 and M4 are, respectively, equal to $73.8 \%$ and $68.0 \%$. Moreover, the proportion of hematite (weak ferromagnetic) is higher to magnetite (ferromagnetic) in both samples. The presence of hematite in the M3 sample is confirmed by 
the Morin transition detected in the corresponding $\mathrm{M}(\mathrm{T})$ curve above. However, in the case of the M4 sample, it should be screened by the large number of paramagnetic silicates. In fact, the corresponding XRD above shows more silicates (amorphous and crystalline) contained in sample M4 than in sample M3. The differences between hyperfine parameters are described in Table 4.

The Mössbauer spectrum for the sample M5 was fitted using: (1) two paramagnetic doublets associated with $\mathrm{Fe}^{3+}$ cations in silicates, (2) two magnetic sextets associated to magnetite, and (3) a distribution of 40 magnetic hyperfine fields $\mathrm{P}\left(\mathrm{B}_{\mathrm{hf}}\right)$ similar to that one for sample M2 and associated to disordered Fe oxides and hydroxides. The majority absorption area in the spectrum corresponds to $\mathrm{Fe}^{3+} /$ silicates (50.2\%). The RAA for magnetite is equal to $35.0 \%$. The sextets corresponding to the magnetite in the Mössbauer spectrum for this sample is assumed taking into account the corresponding $\mathrm{M}(\mathrm{T})$ measurements above in which magnetite is detected by its Verwey transition. The inset of the Mössbauer spectrum for sample M5 presents the hyperfine magnetic field distribution $\mathrm{P}\left(\mathrm{B}_{\mathrm{hf}}\right)$ with $\mathrm{RAA}=14.8 \%$.

Correlating the similarities and differences between samples, the only primary macronutrient for plant found in all of the samples is $\mathrm{K}$. The lack of the other primary macronutrients might confirm the impact of contamination of the soils in Huancavelica reported by other authors [14]. Moreover, the most Western sample (M1) contains more amorphous silicates than the rests suggesting that the original sedimentary rocks might be composed by amorphous silicates and other different minerals are predominant downstream the Ichu River (which flows from West to East). In this way, in the case of iron oxides, magnetite is found in all the other samples, mainly in those located in the North side of the Ichu River (sites M2 and M5). Other elements and minerals, such as Mn and K-silicates are found in the Eastern sites of collection (M2 and M4) which might be associated with the relative high amount of iron and iron oxides in these samples [15]. Thus, the Eastern sites of collection seems to contain different types of iron oxides and other minerals than in the Western sites. However, since it has been reported that iron oxides tend reduce in swamped soils [16], the goethite found in sample M2 might have been formed by the reduction of magnetite swamped in the thermal spring pond located nearby the site of collection.

\section{Conclusions}

Soils samples from an ancient mining city in Peru was characterized by different techniques. Microscopy analysis indicates that soils are composed of two types of particles, one with sharp edged coming from static places, and a second type of traveling particles due to their rounded shape formed by collision between them. The different colours and contrast of the grains indicate that they are composed of different chemical elements and some bright areas suggest the presence of organic materials. The EDX analysis identifies $\mathrm{Si}, \mathrm{Ca}$ and $\mathrm{Fe}$ as the main element, which are typical of soils. XRD analysis identifies amorphous and crystalline silicates for all the samples. The main mineralogical composition identified by XRD are quartz, sanidine, and andradite in sample M1; goethite, calcium carbonate, and microcline in sample M2; augite, cristobalite, calcium carbonate, and quartz in sample M3; muscovite, albite, and quartz in sample M4; and quartz, kaolinite, and grossular in sample M5. About Fe, found as one of the main constituting elements by EDX, it is detected mainly as component in some silicate such as andradite and augite by XRD and iron oxides such as magnetite, hematite and goethite by magnetometry and Mössbauer spectroscopy. The magnetometry analysis for most of the samples reveal 
magnetic competition between ferrimagnetic and antiferromagnetic domains embedded in a paramagnetic matrix. Thus, the coexistence of magnetite, hematite and goethite results in an apparent magnetic alignment signal in the magnetic loops, whereas, the paramagnetic signal should correspond to the non-magnetic minerals present in the samples. In this way, the Verwey and Morin transitions corresponding to magnetite and hematite, respectively are screened by the paramagnetic signal of the silicates. This is confirmed by Mössbauer spectroscopy which detects doubles mainly corresponding to the paramagnetic components, sextets corresponding to the presence of iron oxides such as, magnetite, hematite and goethite. The overlapping between sub-spectra supports the reason why the paramagnetic signals in the magnetization curves do not decay exponentially with temperature, since it screens the ferrimagnetic and antiferromagnetic signals of the iron oxides. Remarkably, in the case of the samples M3 and M4, the ferrimagnetic and antiferromagnetic signals corresponding to the magnetite and hematite, respectively, should be screened by the large number of paramagnetic silicates. This is confirmed by their corresponding XRD which shows more silicates (amorphous and crystalline) contained in sample M4 than in sample M3, and thus the Morin transition slightly appears in the $\mathrm{M}(\mathrm{T})$ curve. In general, the analysed soils are mainly composed of crystalline and amorphous silicates, calcites and iron bearing which are typical from Andean soils.

Supplementary Information The online version contains supplementary material available at https://doi. org/10.1007/s10751-021-01786-8.

Acknowledgements L. De Los Santos and L. Borja thank the Incorporación de Investigadores Program from the CONCYTEC - FONDECYT. UNMSM (Contract No. 12 -2019 - FONDECYT - BM - INC. INV.). The authors are indebted to Mr. Raúl López for his help during collection of the samples, Mr. J. Diaz Solano from the National University of San Marcos for his help during surveying the literature and to Mr. J. Rea Dionicio and Mr. H. Villaverde for the geography information.

Open Access This article is licensed under a Creative Commons Attribution 4.0 International License, which permits use, sharing, adaptation, distribution and reproduction in any medium or format, as long as you give appropriate credit to the original author(s) and the source, provide a link to the Creative Commons licence, and indicate if changes were made. The images or other third party material in this article are included in the article's Creative Commons licence, unless indicated otherwise in a credit line to the material. If material is not included in the article's Creative Commons licence and your intended use is not permitted by statutory regulation or exceeds the permitted use, you will need to obtain permission directly from the copyright holder. To view a copy of this licence, visit http://creativecommons.org/licenses/by/4.0/.

\section{References}

1. C. Contreras and A. Díaz. Los intentos de reflotamiento de la mina de azogue de Huancavelica en el siglo XIX*. América Latina en la historia económica. N0. 29, Jan-June 2008. América Latina en la historia económica. ISSNs 2007-3496 and ISSN 1405-2253.

2. Hagan, N.A.: Contaminación y exposición de Hg Residencial en Huancavelica, Perú (2014)

3. N. Hagan, N. Robins, R. Espinoza, H. Hsu-Kim. Speciation and bioaccessibility of mercury in adobe bricks and dirt floors in Huancavelica, Peru Environ Geochem Health (2015) 37:263-272. https://doi. org/10.1007/s10653-014-9644-1.

4. J. Zeballos. Geología y aplicación geoquímica en la exploración del depósito skarn Huacravilca. Universidad Nacional de San Agustín. Faculty of Geology, Geohysics and Minning. Arequipa-Peru, pp 41, 2014.

5. E. Machacca. Determinación de la composición y correlación mineralógica de los eventos magmáticos en los afloramientos plutónicos en Cabanillas - Puno. Universidad Nacional del Altiplano, Doctoral Thesis. Puno, Peru, pp 35-36, 2020. 
6. M. Mejía. Caracterización mineralógica de los suelos tropicales de la reserva forestal de la Universidad Agraria de la Selva por difractometría de rayos X y Espectroscopía Mössbauer. Universidad Nacional Mayor de San Marcos. Faculty of Physical Science. Lima - Peru, pp 25-26, 2011.

7. A. Sigamony. Magnetic Properties of Augite. (From the Department of Physics, Indian Institute of Science, Bangalore). Received September 1, Año 1944. (Communicated by Sir C. V. Raman, Kt., F.as., N.L.). Pp 261-265.

8. J. W. Stucki, B. A. Goodman, U. Schwertmann. Iron in Soils and Clay Minerals. Department of Agronomy, University of Illinois, Urbana, Illinois, U.S.A. ISBN-13: 978-94-010-8278-5 e-ISBN-13: 978-94-009-4007-9. DO1: 10.1007/978-94-009-4007-9. July 1-13, 1985. Pp 467 al 475.

9. P. A. Schroeder and R.J. Pruett. Fe Ordering in Kaolinite: Insights from ${ }^{29}$ Si and ${ }^{27}$ AI MAS NMR Spectroscopy. Department of Geology, University of Georgia, Athens, Georgia 30602-2501, U.S.A. American Mineralogist, Volume 81, pp 26-38. Año 1996.

10. M. M. Mestdagh, L. Vielvoye and A. J. Herbillon. Iron in Kaolinite: II. The relationship Between Kaolinite Crystallinity and Iron Content. Place Croix du Sud, 1, B-1348 Louvain-la-Neuve, Belgium. Clay Minerals (1980) 15, 1.

11. J.G. Stevens, A.M. Khasanov, J.W. Miller, H. Pollak, and Z. Li. Mössbauer Mineral Handbook. Mössbauer Effect Data Center. The University of North Carolina at Asheville 206 Rhoades Hall, CPO 2311. 2002. www.unca.edu/medc.

12. C. Herzenberg, D. Riley. Mössbauer Resonant Absorption in the garnettype compound ferric molybdate. 117" Research Institute, Chicago, Illinois. U.S.A. 1968. J. Phys. Chem. Solids Vol. 30, pp. 2108-2111.

13. Vandenberghe, R., De Grave, E., de Geyter, G., Landuydt, C.: Characterization of goethite and hematite in a tunisian soil profile by Mössbauer spectroscopy. Clays and Clay Minerals. 34(3), 275-280 (1986)

14. B. Thoms, and N. Robins. Proyecto de Remedacion de mercurio. The Environmental Health Council. Huancavelica-Perú. July 30th 2015. Pp 20.

15. E. García, E. Hernández, O. Acevedo, F. Prieto, H. Luna. $\mathrm{Cu}, \mathrm{Fe}, \mathrm{Mn}$ y Zn en suelos agrícolas localizados al noroeste de Tlaxcala, México. Revista Iberoamericana de Ciencias ISSN 2334-2501. ReIbCi - Vol. 1 No.2. [Pp 205-212]. July 2014 - www.reibci.org.

16. M. Garrido. INTERPRETACIÓN DE ANÁLISIS DE SUELOS. N0. 5/93 HD. Ministry of Agriculture, Fishing and Food. I.S.B.N.: 84-341-0810-0. N.I.P.O.: 253-94-007-5 - Depósito legal: M. 29.238-1994. Rivadeneyra, S. A. - Getafe - Madrid- Spain. 1994.

Publisher's note Springer Nature remains neutral with regard to jurisdictional claims in published maps and institutional affiliations. 